\title{
Dopaminergic Drug Effects on Probability Weighting during Risky Decision Making
}

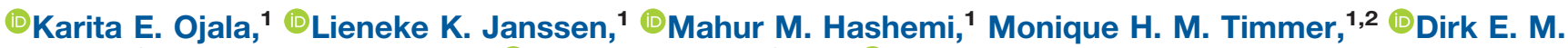
Geurts, ${ }^{1,3}$ Niels P. ter Huurne, ${ }^{1,4}{ }^{-}$Roshan Cools, ${ }^{1,3}$ and ${ }^{-G u i l l a u m e ~ S e s c o u s s e ~}{ }^{1}$

\section{DOI:http://dx.doi.org/10.1523/ENEURO.0330-18.2018}

${ }^{1}$ Donders Institute for Brain, Cognition and Behaviour, Radboud University, Nijmegen, 6525 HR The Netherlands,

${ }^{2}$ Department of Neurology, Radboud University Medical Centre, Nijmegen, 6525 EX The Netherlands, ${ }^{3}$ Department of Psychiatry, Radboud University Medical Centre, Nijmegen, 6525 GA The Netherlands, and ${ }^{4}$ Karakter Child and Adolescent Psychiatry University Centre, Nijmegen, 6525 GC The Netherlands

\begin{abstract}
Dopamine has been associated with risky decision-making, as well as with pathological gambling, a behavioral addiction characterized by excessive risk-taking behavior. However, the specific mechanisms through which dopamine might act to foster risk-taking and pathological gambling remain elusive. Here we test the hypothesis that this might be achieved, in part, via modulation of subjective probability weighting during decision making. Human healthy controls $(n=21)$ and pathological gamblers $(n=16)$ played a decision-making task involving choices between sure monetary options and risky gambles both in the gain and loss domains. Each participant played the task twice, either under placebo or the dopamine $D_{2} / D_{3}$ receptor antagonist sulpiride, in a double-blind counterbalanced design. A prospect theory modelling approach was used to estimate subjective probability weighting and sensitivity to monetary outcomes. Consistent with prospect theory, we found that participants presented a distortion in the subjective weighting of probabilities, i.e., they overweighted low probabilities and underweighted moderate to high probabilities, both in the gain and loss domains. Compared with placebo, sulpiride attenuated this distortion in the gain domain. Across drugs, the groups did not differ in their probability weighting, although gamblers consistently underweighted losing probabilities in the placebo condition. Overall, our results reveal that dopamine $D_{2} / D_{3}$ receptor antagonism modulates the subjective weighting of probabilities in the gain domain, in the direction of more objective, economically rational decision making.
\end{abstract}

Key words: dopamine; pathological gambling; probability weighting; prospect theory; reward; risky decision making

\section{Significance Statement}

Dopamine has been implicated in risky decision making and gambling addiction, but the exact mechanisms underlying this influence remain partly elusive. Here we tested the hypothesis that dopamine modulates subjective probability weighting, by examining the effect of a dopaminergic drug on risk-taking behavior, both in healthy individuals and pathological gamblers. We found that selectively blocking dopamine $D_{2} / D_{3}$ receptors diminished the typically observed distortion of winning probabilities, characterized by an overweighting of low probabilities and underweighting of high probabilities. This made participants more linear in their subjective estimation of probabilities and thus more rational in their decision-making behavior. Healthy participants and pathological gamblers did not differ in their risk-taking behavior, except in the placebo condition in which gamblers consistently underweighted losing probabilities.

Received September 22, 2017; accepted February 26, 2018; First published March 16, 2018.

The authors declare no competing financial interests.
Author contributions: R.C. and G.S. designed research; L.K.J., M.M.H., M.H.M.T., D.E.M.G., N.P.t.H., and G.S. performed research; K.E.O. and G.S. analyzed data; K.E.O, R.C., and G.S. wrote the paper. 


\section{Introduction}

A wealth of animal and human studies has implicated dopamine in risk-taking behavior. Pharmacological studies in rodents have shown that drugs blocking dopamine $D_{1}$ and $D_{2} / D_{3}$ receptors generally decrease risk taking, whereas drugs enhancing dopamine $D_{1}$ and $D_{2} / D_{3}$ receptor activity generally increase risk-taking (St Onge and Floresco, 2009; Zeeb et al., 2009; St Onge et al., 2010; Barrus and Winstanley, 2016). Similarly, in humans, boosting dopaminergic transmission with drugs such as L-Dopa and $D_{2} / D_{3}$ receptor agonists has been shown to increase risk-taking behavior (Riba et al., 2008; Djamshidian et al., 2010; Voon et al., 2011; Rutledge et al., 2015; Rigoli et al., 2016). Furthermore, studies in both humans and animals have reported that variations in dopamine levels due to genetic manipulations or natural variations in the expression of the dopamine transporter gene are associated with changes in risk preferences (Mata et al., 2012; van Enkhuizen et al., 2014). Yet, the specific neurocognitive mechanisms through which increased dopaminergic transmission would increase risk-taking behavior remain partly elusive. Some studies have suggested an influence via reward valuation mechanisms (Zhong et al., 2009) while other studies have shown that this influence is exerted via a change in value-independent gambling propensity (Rutledge et al., 2015; Rigoli et al., 2016; Timmer et al., 2017). Here, we focus on a less well-investigated hypothesis, which is the role of dopamine on the subjective weighting of probabilities, both in healthy participants and individuals suffering from pathological gambling, a psychiatric disorder characterized by excessive risk taking.

A useful and popular framework for examining how dopamine influences probability weighting is prospect theory (Kahneman and Tversky, 1979). Prospect theory posits that the departure of human agents from rational economic decision-making (i.e., expected value maximization) results from diminishing sensitivity to outcome value on the one hand and nonlinear weighting of probabilities on the other hand. People typically overweight low probabilities and underweight moderate to high probabilities, which results in an inverted-S-shaped probability weight-

G.S. was supported by a Veni grant from the Netherlands Organisation for Scientific Research (NWO).

K. E. Ojala's present address: Department of Psychiatry, Psychotherapy, and Psychosomatics, Psychiatric University Hospital 8032 Zurich; Neuroscience Centre Zurich, University of Zurich, 8057 Zurich, Switzerland.

L. K. Janssen's present address: Department of Neurology, Max Planck Institute for Human Cognitive and Brain Sciences; Leipzig University Medical Center, IFB Adiposity Diseases, 04103 Leipzig, Germany.

Acknowledgements: We thank Romain Ligneul, Payam Piray, Bram Zandbelt, and Filip Melinščak for helpful discussions on data analysis and visualization.

Correspondence should be addressed to either of the following: Karita E. Ojala, Department of Psychiatry, Psychotherapy, and Psychosomatics, Psychiatric University Hospital, University of Zurich, Lenggstrasse 31, 8032 Zurich, Switzerland, E-mail: karita.ojala@uzh.ch; or Guillaume Sescousse, Donders Centre for Cognitive Neuroimaging, PO Box 9101, 6500 HB Nijmegen, The Netherlands, E-mail: g.sescousse@donders.ru.nl.

DOI:http://dx.doi.org/10.1523/ENEURO.0330-18.2018

Copyright @ 2018 Ojala et al.

This is an open-access article distributed under the terms of the Creative Commons Attribution 4.0 International license, which permits unrestricted use, distribution and reproduction in any medium provided that the original work is properly attributed. ing function and a diminished sensitivity to changes in probabilities in the medium range (Fig. 1B). A previous PET study in humans has shown that the degree of nonlinear probability weighting in the gain domain is correlated with striatal dopamine $D_{1}$ receptor availability across subjects (Takahashi et al., 2010). Work with fMRI has also shown that probability distortion is accompanied by similarly distorted patterns of striatal BOLD activity (Hsu et al., 2009). Here, we aimed to establish a causal link between dopamine and probability distortion using a pharmacological manipulation.

Dopamine has been linked to pathological gambling (PG, also called gambling disorder), an addictive disorder characterized by excessive financial risk-taking in the face of negative consequences. Initial evidence for the role of dopamine in PG came from the clinical observation that a subset of patients with Parkinson's disease develop PG symptoms after receiving dopaminergic replacement therapy, in particular dopamine $D_{2} / D_{3}$ receptor agonists with high affinity for $D_{3}$ receptors (Voon et al., 2009; Seeman, 2015). This concurs with recent evidence showing that $P G$ is characterized by a hyper-dopaminergic state (Boileau et al., 2014; van Holst et al., 2017), and the prominent role of dopamine $D_{3}$ receptors in human and rat models of $P G$ (Payer et al., 2014; Lobo et al., 2015). However, the specific mechanisms through which dopamine $D_{2} / D_{3}$ receptor activity may act to foster PG remain elusive. In our previous study (Ligneul et al., 2013), pathological gamblers showed an elevation in their probability weighting function compared with healthy controls, reflecting an increased preference for risk or "optimism bias" in the gain domain (Gonzalez and Wu, 1999). Based on this observation, we aimed to test whether sulpiride, a selective dopamine $D_{2} / D_{3}$ receptor antagonist, could normalize risk-taking behavior in pathological gamblers, by decreasing the elevation of subjective probability weighting.

To test the above hypotheses, we conducted a pharmacobehavioral study using a within-subject counterbalanced design. pathological gamblers and healthy controls were asked to make choices between safe and risky options, both under placebo and sulpiride. Of note, feedback was not provided, to avoid potential learning effects and reinforcement-induced changes in choice strategy (Schonberg et al., 2011). We used prospect theory modeling to estimate subjective probability weighting and sensitivity to outcome value, separately in the gain and loss domains. Our main objective was to assess the effect of sulpiride on the two main characteristics of the probability weighting function, i.e., nonlinear distortion (sensitivity to changes in probability) and elevation (optimism bias). At a more exploratory level, we were also interested in comparing those effects in the gain and loss domains, given extensive literature showing differential effects of dopamine on gains versus losses (Frank et al., 2004; Pessiglione et al., 2006).

\section{Materials and Methods}

\section{Participants}

We recruited 22 healthy controls and 22 pathological gamblers, all men, following an in-depth structured psychiatric interview administered by a medical doctor (MINI 
A

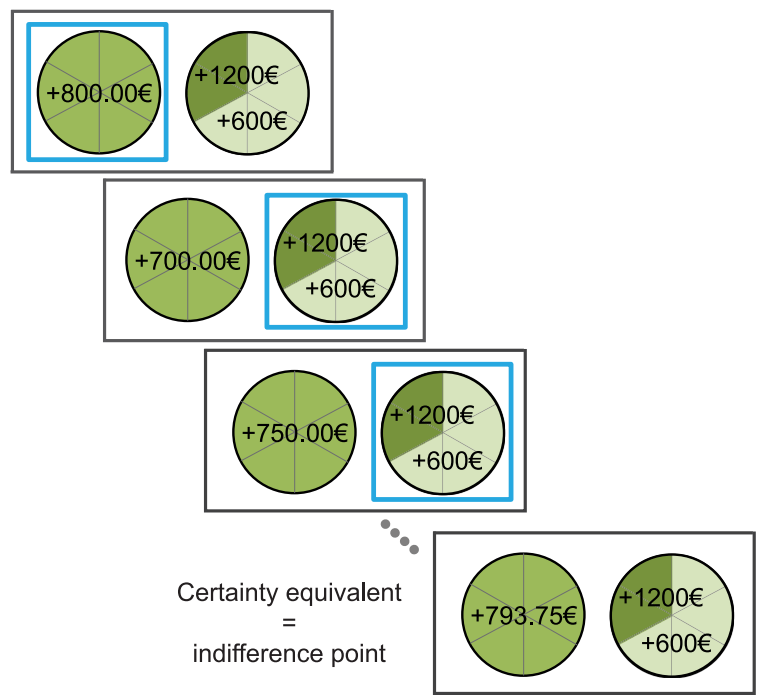

B

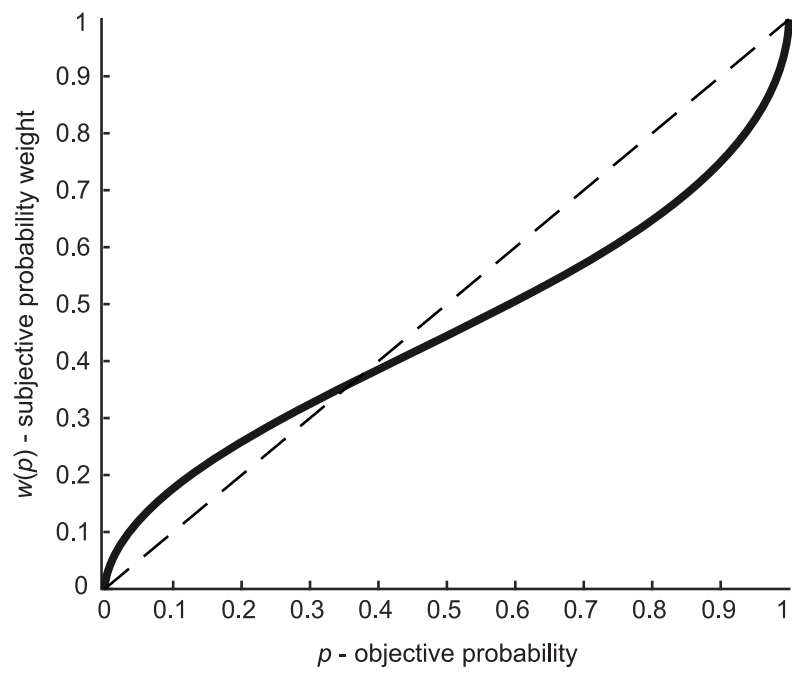

Figure 1. The gambling task and the probability weighting function of prospect theory. $\boldsymbol{A}$, Each trial consisted of a self-paced choice between a sure option (on the left) and a risky gamble (on the right), followed by visual confirmation of the choice (a frame around the chosen option) and fixation. The sure amount in the next trial was adjusted based on the choice (increased if gamble was chosen, decreased if the sure option was chosen), with the gamble being fixed. After six choices, the sure amount that was reached provided an indifference point between the two options, defined as the certainty equivalent of the gamble. A new series of choices involving a new gamble was then started (in total, 10 gambles in the gain domain and 10 gambles in the loss domain). No feedback was provided on the outcome of the choices. $\boldsymbol{B}$, The solid black line represents a typical probability weighting function, with overweighting of low probabilities and underweighting of moderate to high probabilities. The dashed diagonal line represents neutrality with regard to sensitivity to probabilities.

Plus; Sheehan et al., 1998). One gambler was excluded because his data were accidentally not written to the log file for one drug session. One control participant and five gamblers were excluded due to extreme behaviors violating core assumptions of prospect theory (for more details, see Statistical analysis). Therefore, the reported results are based on data from 21 healthy controls and 16 gamblers. The present task was part of a larger study for which the participants were paid $€ 50$ on each session. The other tasks in the study were a reversal learning task (Janssen et al., 2015), a slot machine task measuring sensitivity to near-misses (Sescousse et al., 2016), and a mixed gamble task measuring loss aversion. All participants provided written informed consent, which was approved by the regional research ethics committee (Commissie Mensgebonden Onderzoek, region ArnhemNijmegen).

pathological gamblers were recruited through advertisement $(N=13)$ and addiction clinics $(N=3)$. None of the gamblers was in treatment at the time of testing, except for one who was just starting a cognitive behavioral therapy for his gambling problems. Control participants were recruited through advertisement. All gamblers, with the exception of one, qualified as pathological gamblers $(\geqslant 5$ DSM-IV criteria for pathological gambling; American Psychiatric Association, 2000). One gambler qualified as problem gambler as he met only four DSM-IV criteria. The severity of gambling symptoms was assessed using the South Oaks Gambling Screen (SOGS; Lesieur and Blume, 1987). All gamblers had a minimum SOGS score of 6 (range, 6-18), whereas healthy controls, with the excep- tion of two participants, had a SOGS score of 0 (range, $0-2)$.

The two groups were matched for age, net income, body mass index, and verbal IQ (Table 1). Participants were excluded if they consumed more than four alcoholic beverages daily; were using psychotropic medication; had a lifetime history of schizophrenia, bipolar disorder, attention deficit hyperactivity disorder, autism, eating disorder, anxiety disorder, or obsessive-compulsive disorder; or had a major depressive episode in the preceding six months. Given the high comorbidity between pathological gambling and other psychiatric disorders (Lorains et al., 2011), gamblers with the following comorbidities were included in the sample: past cannabis dependence (more than five months; $N=1$ ); lifetime history of dysthymia $(N=1)$; and remitted post-traumatic stress disorder (remitted more than four years; $N=1$ ). One gambler had used cannabis weekly in the preceding six months but did not meet the DSM-IV criteria for abuse/dependence. The control participants did not have any history of substance abuse or dependence. A number of self-report questionnaires were further used to characterize the participants (Table 1).

\section{Pharmacological manipulation}

Participants were tested once after receiving a sulpiride pill (Dogmatil, $400 \mathrm{mg}$ ), and once after receiving a placebo pill filled with microcrystalline cellulose. The order of administration was randomized according to a double-blind, crossover design (placebo-sulpiride: 10 controls, eight gamblers; sulpiride-placebo: 11 controls, eight gamblers). 
Table 1. Demographic characteristics and questionnaire scores

\begin{tabular}{|c|c|c|c|c|c|c|c|}
\hline \multirow[t]{2}{*}{ Variable } & \multicolumn{3}{|c|}{ Healthy Controls $(n=21)$} & \multicolumn{3}{|c|}{ Pathological Gamblers $(n=16)$} & \multirow[t]{2}{*}{$p$} \\
\hline & Range & M & SD & Range & $\mathrm{M}$ & SD & \\
\hline Age & $18-52$ & 32.1 & 11.4 & $21-50$ & 35.8 & 8.8 & 0.29 \\
\hline Net income $(€)$ & $0-3570$ & 1691 & 1123 & $750-3250$ & 1750 & 949 & 0.87 \\
\hline Body mass index & $18.3-30.9$ & 23.1 & 3.2 & 20.8-26.9 & 23.9 & 2.0 & 0.38 \\
\hline SOGS & $0-2$ & 0.2 & 0.5 & $6-18$ & 12.4 & 3.9 & $<0.001$ \\
\hline FTND & $0-5$ & 0.6 & 1.4 & $0-8$ & 2.5 & 2.9 & 0.014 \\
\hline Number of current smokers & - & 10 & - & - & 10 & - & 0.37 \\
\hline AUDIT & $0-14$ & 6.2 & 3.8 & $0-15$ & 7.7 & 4.6 & 0.27 \\
\hline HADS anxiety & $0-12$ & 2.7 & 2.8 & $1-12$ & 4.9 & 3.4 & 0.035 \\
\hline HADS depression & $0-10$ & 1.6 & 2.3 & $0-15$ & 4.9 & 4.4 & 0.006 \\
\hline Verbal IQ & $85-128$ & 106 & 9.5 & $77-123$ & 103 & 12.3 & 0.43 \\
\hline
\end{tabular}

M, Mean; SD, Standard Deviation; FTND, Fagerström test for nicotine dependence (Heatherton et al., 1991); AUDIT, alcohol use disorders identification test (Saunders et al., 1993); HADS, hospital anxiety and depression scale (Zigmond and Snaith, 1983).

The test sessions were separated by at least one week. Sulpiride was chosen as the dopamine-modulating drug in this study based on a few reasons. First, it is one of the most selective agents acting on dopamine $D_{2} / D_{3}$ receptors. As mentioned earlier, $D_{2} / D_{3}$ agents are known to cause pathological gambling symptoms in a subset of patients with Parkinson's disease. Moreover, sulpiride has been shown to modulate the sensitivity to reward and punishment during learning in human studies (Eisenegger et al., 2014; van der Schaaf et al., 2014). Background neuropsychological functioning, physiological measures and subjective mood were measured at several time points during the protocol to check for nonspecific effects of sulpiride; no such effects were observed. The risky decision-making task was performed $\sim 3 \mathrm{~h} 15$ min after drug intake, thus coinciding with high plasma concentrations of sulpiride (von Bahr et al., 1991).

\section{Experimental design and statistical analysis \\ Experimental task}

We used a "certainty equivalent" procedure (Fig. 1A) based on the protocol developed by Abdellaoui et al. (2008, 2011). Participants made series of hypothetical decisions between a sure amount of money (either a gain or a loss) and a gamble (either a pure-gain or pure-loss gamble). In each series of decisions, the gamble was fixed and the sure amount was iteratively adjusted to converge toward a certainty equivalent corresponding to the sure amount that felt subjectively equivalent to the gamble. There were 10 series of decisions (i.e., 10 different gambles) in the gain domain and 10 series of decisions in the loss domain (Table 2).

In each series of decisions, the sure amount offered on the first trial corresponded to the expected value of the

Table 2. Gambles with varying outcomes and probabilities

\begin{tabular}{llllccccccc}
\hline & \multicolumn{1}{c}{ Gamble index $i$} \\
Variable & 1 & 2 & 3 & 4 & 5 & 6 & 7 & 8 & 9 & 10 \\
$x$ & 1200 & 1200 & 600 & 1200 & 600 & 1000 & 1200 & 1200 & 1200 & 1200 \\
$p$ & $1 / 6$ & $2 / 6$ & $2 / 6$ & $2 / 6$ & $2 / 6$ & $2 / 6$ & $2 / 6$ & $3 / 6$ & $4 / 6$ & $5 / 6$ \\
$y$ & 0 & 0 & 0 & 600 & 300 & 400 & 900 & 0 & 0 & 0
\end{tabular}

$x$ is the larger amount of money in the gamble that could be won or lost with probability $p ; y$ is the smaller amount of money in the gamble that could be won or lost with probability $1-p . x$ and $y$ are in $€$. For losses, the amounts of money were the same but negative. gamble. On subsequent trials, the sure amount was adjusted based on the previous choice according to the bisection method (Abdellaoui et al., 2011), such that it was increased if the gamble was chosen and decreased if the sure option was chosen. This staircase procedure drove the participants toward their certainty equivalent, that is, the indifference point between the risky and safe options. The decision for each trial was self-paced, after which the participant's choice was highlighted on the screen. Participants did not receive any feedback on their choice. Each series of decisions consisted of six trials, which is considered enough to provide reliable certainty equivalent estimates (Abdellaoui et al., 2011). In order to check for errors and random responses, each series ended with two control trials that required choosing between the gamble and a sure amount slightly above or below the estimated certainty equivalent. If the participant's response was not consistent with previous choices, the series was repeated. Participants were not explicitly informed about these control trials. We checked that the number of repetitions was not significantly different between healthy controls and pathological gamblers (gain domain: $Z=$ $0.55, p=0.60$; loss domain: $Z=1.31, p=0.20$ ), between the placebo and sulpiride drug conditions (gain domain: $Z=$ 1.66, $p=0.098$; loss domain: $Z=0.36, p=0.72$ ), or between gains and losses in general $(Z=1.47, p=0.14)$.

In total, participants went through a minimum of 160 experimental trials ( 10 series $*[6$ choices +2 control trials] $* 2$ [gain/loss]). The task was the same in the loss domain but with negative amounts of money. Gain and loss trials were presented in separate blocks and the order of the blocks was counterbalanced across participants and drug sessions. The order of the specific gambles (Table 2) within gain and loss blocks was randomized. The task was performed on a computer and the task presentation was created with the Psychophysics Toolbox 2 (Brainard, 1997) for Matlab.

\section{Behavioral modeling}

We used the semi-parametric method introduced by Abdellaoui et al. (2008, 2011; see also Fox and Poldrack, 2014) to estimate the value and probability weighting functions of prospect theory. This procedure was employed separately for gains and losses and for the drug and placebo conditions, within each individual participant. 
In the first step of the procedure, the certainty equivalents of the gambles with varying amounts of money but a fixed probability of $2 / 6$ (gamble indices $i=2, \ldots, 7$ in Table 2) were used to estimate the probability weight $w(2 / 6)$ as well as the curvature of a parametrically defined version of the value function $v(\bullet)$. By definition, the utility of each gamble is equal to the utility of its certainty equivalent and, based on prospect theory, we can write:

$$
v(C E)=w(p) v(x)+(1-w(p)) v(y)
$$

where $C E$ is the certainty equivalent, $x$ is the amount of money to be won with probability $p$ and $y$ is the amount of money to be won with probability $1-p$. Assuming a power function $x^{\alpha}$ for $v(\bullet)$ (Fox and Poldrack, 2014), where $\alpha$ quantifies sensitivity to outcome values, we can further write:

$$
C E=\left[w(p)\left(x^{\alpha}-y^{\alpha}\right)+y^{\alpha}\right]^{\frac{1}{\alpha}}
$$

Using a nonlinear least squares procedure (Isqcurvefit function in Matlab), we then estimated the optimal parameter values $\alpha$ and $w(2 / 6)$ that minimized the least squares $|C E(i)-\hat{C E}(i)|$, where $\hat{C E}(i)$ are the estimated certainty equivalents for gambles indices $i=2, \ldots, 7$, expressed as:

$$
\hat{C E}(i)=\left[w(2 / 6)\left(\left(x_{i}\right)^{\alpha}-\left(y_{i}\right)^{\alpha}\right)+\left(y_{i}\right)^{\alpha}\right]^{\frac{1}{\alpha}}
$$

In the second step of the procedure, nonparametric estimates of the remaining probability weights $w(1 / 6)$, $w(3 / 6), w(4 / 6)$ and $w(5 / 6)$ were derived from the certainty equivalents of the corresponding gambles (gamble indices $i=1,8,9$ and 10 in Table 2). Since $y=0$ in these gambles, based on Equation 2, each probability weight can be calculated as follows:

$$
C E=\left[w(p) x^{\alpha}\right]^{\frac{1}{\alpha}} \Leftrightarrow w(p)=\frac{C E^{\alpha}}{x^{\alpha}}
$$

Based on these probability weights, we further derived a parametric estimation of the probability weighting function. We used a nonlinear least squares procedure to estimate the two-parameter function proposed by Lattimore et al. (1992), in which the sensitivity to changes in probabilities is quantified with distortion parameter $\gamma$, and the optimism about risk is quantified with elevation parameter $\delta$ :

$$
w(p)=\frac{\delta p^{\gamma}}{\delta p^{\gamma}+(1-p)^{\gamma}}
$$

To avoid local minima in our least squares estimations, we used an approach with randomized starting values. The two-step estimation procedure was run 200 times with starting values randomly drawn from $[0,5]$ for parameters $\alpha, \delta$, and $\gamma$, and from $[0,1]$ for $w(2 / 6)$. The resulting prospect theory parameters with the smallest squared norm of the residuals ("resnorm"), reflecting the goodness-of-fit between the model and the data, were selected for the subsequent statistical analysis. Note that the resnorm values did not differ between drugs or groups for either of the two least square estimations (paired and independent $t$ tests, respectively: all $p_{\text {corrected }}>0.2$ ), suggesting that the average goodness-of-fit was comparable across drugs and groups.

\section{Statistical analysis}

One control participant and four pathological gamblers were excluded from subsequent group analyses based on their certainty equivalents. For all these participants, the absolute value of their certainty equivalent was higher for Gamble $1(x= \pm € 1200, p=1 / 6)$ than for Gamble 10 $(x= \pm € 1200, p=5 / 6)$, in at least one of the four conditions of interest (gain/loss $*$ placebo/sulpiride). This behavior violates the basic assumption of positive monotonicity in the evaluation of probabilities. One pathological gambler was further excluded due to extremely risk averse behavior ( $\alpha$ value over three standard deviations away from the mean) that likely resulted from a fear of losing control and relapsing into compulsive gambling (as reported by the participant during debriefing). While the primary analyses were performed on the reduced sample resulting from these exclusions, we also performed analyses on the full sample to verify that our results were not distorted by our exclusion procedure (for details, see Results, Sensitivity analyses).

Prospect theory parameters $\alpha, \delta$, and $\gamma$ were compared across groups and drug conditions, separately in the gain and loss domains, using nonparametric statistics due to the non-normal distribution of the data. Main effects of the within-subject Drug factor were assessed using Wilcoxon tests. Main effects of between-subject Group factor were assessed using Mann-Whitney $U$ tests, after parameters were averaged across drug sessions. Drug-by-Group as well as Drug-by-Drug Order interactions were examined with Mann-Whitney $U$ tests comparing sulpiride minus placebo values between groups. Bonferroni correction was used for the six comparisons performed for each dependent variable (parameters $\alpha, \delta$, and $\gamma$ ): the two main effects of Drug and Group as well as their interaction, times the two contexts (gains and losses). Therefore, the corrected $p$ values correspond to the uncorrected $p$ values multiplied by 6 . For effect sizes, we use the Common Language Effect sizes (CLE; Wuensch, 2015; Grissom and Kim, 2012) for intuitive interpretation. For the MannWhitney $U$ tests, the CLE was calculated as $U$ divided by the product of the two groups' sample sizes. For the Wilcoxon tests, the CLE was calculated as the number of positive differences (in favor of sulpiride over placebo) divided by the number of comparisons, that is, the total sample size. Therefore, the CLE represents the probability of a randomly selected value from one group/condition being higher than a randomly sampled value from the other group/condition. For both tests, there is no difference between the groups or conditions at CLE $=0.5$.

\section{Code accessibility}

The data and code used to produce the reported results are available as Extended Data 1. The data and code can be found with DOI references and addresses doi.org/10.6084/m9.figshare.5311354 and doi.org/10. $6084 / \mathrm{m} 9$. figshare.5311456, respectively. The code was 
Table 3. Estimates of prospect theory parameters

\begin{tabular}{|c|c|c|c|c|c|c|c|c|}
\hline \multirow{3}{*}{ Parameter } & \multicolumn{4}{|c|}{ Controls } & \multicolumn{4}{|c|}{ Gamblers } \\
\hline & \multicolumn{2}{|c|}{ Placebo } & \multicolumn{2}{|c|}{ Sulpiride } & \multicolumn{2}{|c|}{ Placebo } & \multicolumn{2}{|c|}{ Sulpiride } \\
\hline & Mdn & IQR & Mdn & IQR & Mdn & IQR & Mdn & IQR \\
\hline rain & 0.74 & 0.66 & 0.80 & 0. & 0.80 & & & 0.81 \\
\hline$\alpha_{\text {losses }}$ & 1.02 & 1.1 & & & & & & 0.95 \\
\hline yains & 0.99 & 0.86 & 0.93 & $0 . \varepsilon$ & 0.90 & & & 0.61 \\
\hline osses & 1.08 & 0.80 & 0.83 & 0.6 & 0.42 & 0. & 0. & 0.99 \\
\hline & 0.55 & 0.50 & 0.66 & 0.5 & 0.64 & 0. & 0.8 & 0.49 \\
\hline$\gamma_{\text {losse }}$ & 0.97 & 0.61 & 1.06 & 0.60 & 0.88 & 0.78 & 0.72 & 0.72 \\
\hline
\end{tabular}

Mdn, median; IQR, interquartile range.

run with a standard Windows 7 Professional 64-bit desktop computer (Intel Xeon CPU E5-1620, 16GB RAM), both with MATLAB R2013a and R2016a (RRID: SCR_001622).

\section{Results}

Table 3 reports group estimates for parameters $\gamma, \delta$, and $\alpha$ in the study.

\section{Sensitivity to changes in probabilities (distortion parameter $\gamma$ )}

A change in the distortion parameter $\gamma$ of the probability weighting function represents a change in the nonlinear weighting of probabilities and thus the sensitivity to changes in probability. The distortion parameter $\gamma$ did not significantly differ between control participants and pathological gamblers either in the gain domain $(Z=1.47$, $\left.p_{\text {uncorr }}=0.15, \mathrm{CLE}=0.64\right)$ or the loss domain $(Z=-1.13$, $p_{\text {uncorr }}=0.27, \mathrm{CLE}=0.39$ ).

However, there was a significant effect of the drug on $\gamma$ in the gain domain $\left(Z=2.96, p_{\text {uncorr }}=0.003, p_{\text {corr }}=\right.$ 0.018 , CLE $=0.70$ ). Specifically, participants had higher values of $\gamma$ under sulpiride $(M d n=0.69)$ than under placebo $(M d n=0.58)$, indicating lower levels of distortion of the probability weighting function in the sulpiride condition (Fig. 2). In the loss domain, there was no difference between placebo and sulpiride $\left(Z=0.36, p_{\text {uncorr }}=0.72\right.$, $C L E=0.41)$. Drug effect did not interact with drug order in either the gain $\left(Z=1.46, p_{\text {uncorr }}=0.15, \mathrm{CLE}=0.65\right)$ or the loss domain $\left(Z=0.58, p_{\text {uncorr }}=0.58, C L E=0.56\right)$, indicating no reliable session effects. The drug effect (sulpiride-placebo) was not significantly different between control participants and pathological gamblers in the gain domain $\left(Z=0.55, p_{\text {uncorr }}=0.60\right.$, CLE $\left.=0.55\right)$ or in the loss domain $\left(Z=-2.02, p_{\text {uncorr }}=0.044, p_{\text {corr }}=0.26\right.$, CLE $=$ 0.30 ). Figure 3 illustrates the shape of the probability weighting function separately for the gain/loss and placebo/ sulpiride conditions in each group.

\section{Optimism about risk (elevation parameter $\delta$ )}

A change in the elevation parameter $\delta$ of the probability weighting function represents a shift in the weighting of the entire probability range, thus reflecting overall optimism or pessimism about risk. The elevation parameter $\delta$ did not significantly differ between control participants and pathological gamblers either in the gain domain $(Z=$ $-1.41, p_{\text {uncorr }}=0.17, \mathrm{CLE}=0.36$ ) or in the loss domain $\left(Z=-1.96, p_{\text {uncorr }}=0.051, p_{\text {corr }}=0.31, \mathrm{CLE}=0.31\right)$. Moreover, there was no significant effect of drug either in the gain domain $\left(Z=-0.31, p_{\text {uncorr }}=0.76, C L E=0.43\right)$ or in the loss domain $\left(Z=0.39, p_{\text {uncorr }}=0.70\right.$, CLE $=$ 0.59 ). Finally, the drug effect (sulpiride-placebo) was not significantly different between control participants and pathological gamblers in the gain domain $(Z=-0.74$, $\left.p_{\text {uncorr }}=0.48, C L E=0.43\right)$ or in the loss domain $(Z=$ $1.57, p_{\text {uncorr }}=0.12$, CLE $=0.65$ ).

For optimal comparison with our previous study, in which we found a group difference in $\delta$ in the gain domain (Ligneul et al., 2013), we further compared the groups in the placebo condition alone. This analysis did not reveal a significant group difference in $\delta$ in the gain domain $(Z=$ $0.03, p_{\text {uncorr }}=1.0, C L E=0.50$ ) but did reveal a significant difference in the loss domain $\left(Z=-2.9, p_{\text {uncorr }}=0.003\right.$, $p_{\text {corr }}=0.018$, CLE $=0.22$ ). Specifically, pathological gamblers had lower values of $\delta(M d n=0.42)$ than control participants $(M d n=1.08)$, indicating lower elevation of the probability weighting function in the loss domain (Fig. $3 C, D)$.

\section{Sensitivity to outcomes (curvature parameter $\alpha$ )}

Since our procedure also enabled us to measure the curvature parameter of the value function, we also examined potential effects of group and drug on this parameter. Nonparametric tests indicated that there was no significant difference between control participants and pathological gamblers either in the gain domain $(Z=0.86$, $p_{\text {uncorr }}=0.40$, CLE $\left.=0.58\right)$ or in the loss domain $(Z=$ $\left.1.17, p_{\text {uncorr }}=0.25, \mathrm{CLE}=0.61\right)$. Moreover, there was no effect of drug in the gain domain $\left(Z=1.53, p_{\text {uncorr }}=0.13\right.$, CLE $=0.62)$ or in the loss domain $\left(Z=-1.21, p_{\text {uncorr }}=\right.$ 0.23 , CLE $=0.41$ ). Finally, the drug effect (sulpirideplacebo) was not significantly different between control participants and pathological gamblers in the gain domain $\left(Z=1.96, p_{\text {uncorr }}=0.051, p_{\text {corr }}=0.31, \mathrm{CLE}=0.69\right)$ or in the loss domain $\left(Z=-1.69, p_{\text {uncorr }}=0.10, C L E=0.34\right)$.

\section{Sensitivity analyses}

To confirm the pattern of our main result on probability distortion, we performed an analysis of the probability weights themselves, which were obtained using a semiparametric procedure, as opposed to the parametric estimation of $\gamma$. Specifically, we performed a 2 (groups) $\times 2$ (drugs) $\times 5$ (probability levels: 1/6, 2/6, 3/6, 4/6, and 5/6) ANOVA on the probability weights $w(p)$ in the gain domain. We observed a significant interaction of drug and probability level on the $w(p)\left(F_{(2.7,94.495)}=3.21, p=0.031\right.$, $\eta^{2}=0.084$ ), thus strengthening our main result that sulpiride differentially modulates small versus medium-tolarge probability weights. However, matched samples post-hoc $t$ tests between the $w(p)$ for the two drug conditions failed to reach significance $\left(w(1 / 6): t_{(36)}=1.15, p=\right.$ $0.26, w(2 / 6): t_{(36)}=1.39, p=0.17, w(3 / 6): t_{(36)}=0.62$, $p=0.54, w(4 / 6): t_{(36)}=-0.15, p=0.26, w(5 / 6): t_{(36)}=$ $-1.41, p=0.17)$.

We also repeated our estimation procedure with different variations to check the robustness of our results despite small changes in the way the parameters were estimated. First, we estimated parameters $\delta$ and $\gamma$ using the Prelec version of the probability weighing function 
A

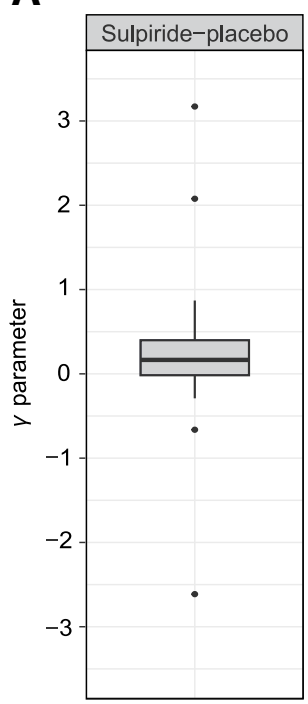

C

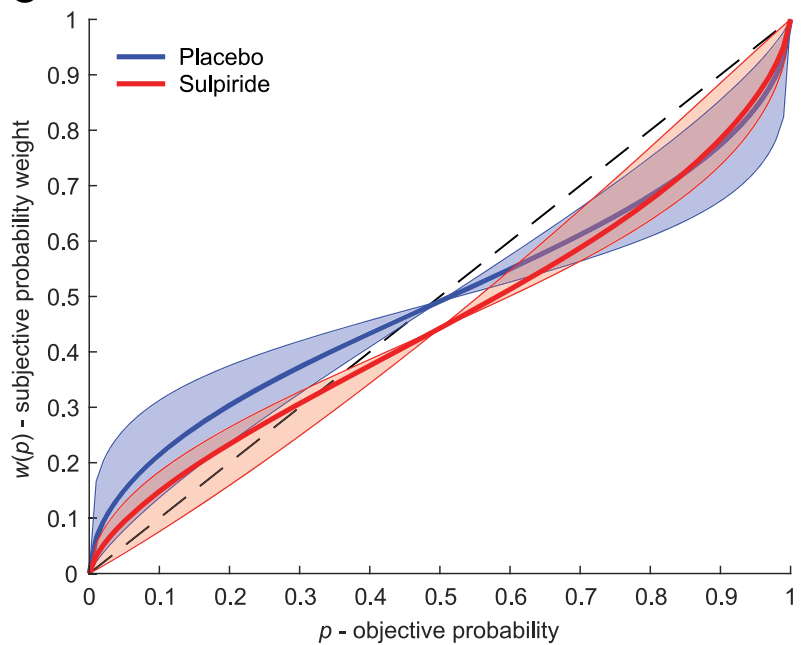

B

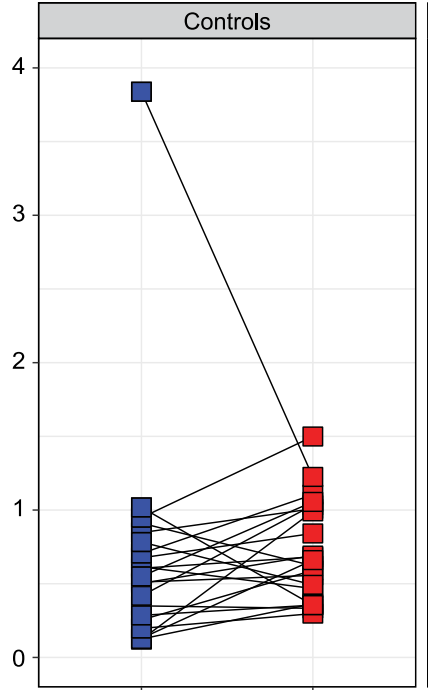

Placebo

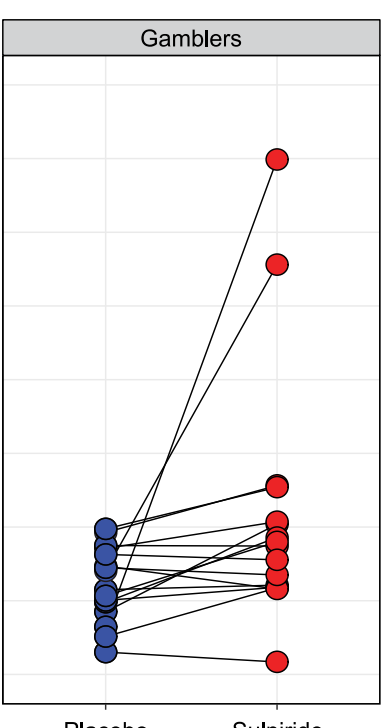

Placebo Sulpiride

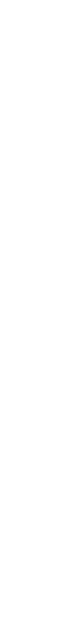

Figure 2. Dopaminergic modulation of probability distortion. A, Boxplot illustrating the drug effect (sulpiride-placebo) on the distortion parameter $\gamma$ of the probability weighting function in the gain domain, across all participants. Box height represents the interquartile range (IQR), black line represents the median, and whiskers represent the largest and smallest values no further than $1.5 * I Q R$. Single data points are values located outside the whiskers. $\boldsymbol{B}$, Within-subject paired observations of $\gamma$ estimates in the placebo and sulpiride conditions for both experimental groups (different illustration of the result presented in Fig. 2A). C, Fitted probability weighting function, based on the median estimates of $\delta$ (elevation) and $\gamma$ (distortion) parameters across all participants. The shaded areas illustrate the variance of $\gamma$ across participants, with the boundaries corresponding to the probability weighting function plotted with median $\delta$, and 25th and 75th percentile $\gamma$.

(Prelec, 1998), instead of the Lattimore version (Lattimore et al., 1992). The Prelec function is defined by the following equation:

$$
w(p)=e^{-\delta(-\ln p) \gamma}
$$

The parameters $\delta$ and $\gamma$ have the same interpretation as in the Lattimore function, except that the degree of elevation decreases when the parameter $\delta$ increases. When the same analysis was conducted on the parameter estimates obtained with the Prelec function, the drug effect on the distortion parameter $\gamma$ remained significant $(Z=$ $2.71, p_{\text {uncorr }}=0.007, p_{\text {corr }}=0.032, \mathrm{CLE}=0.70$ ), emphasizing that sulpiride decreases the distortion of the prob- ability weighting function (i.e., increases the parameter $\gamma$ ) compared with placebo.

In addition, the drug effect on the distortion parameter $\gamma$ remained significant $\left(Z=2.96, p_{\text {uncorr }}=0.003, p_{\text {corr }}=0.018\right.$, CLE $=0.70)$ when we used a linear value function $(\alpha=1)$ instead of a power function $\left(x^{\alpha}\right)$, a common assumption we made in our previous study (Ligneul et al., 2013).

Furthermore, using the original analysis with the power and Lattimore functions, the drug effect on the distortion parameter $\gamma$ remained significant when we excluded the one participant with past cannabis dependence $(Z=2.83$, $p_{\text {uncorr }}=0.005, p_{\text {corr }}=0.030$, CLE $=0.69$ ). It also remained significant when we included all possible partici- 
A

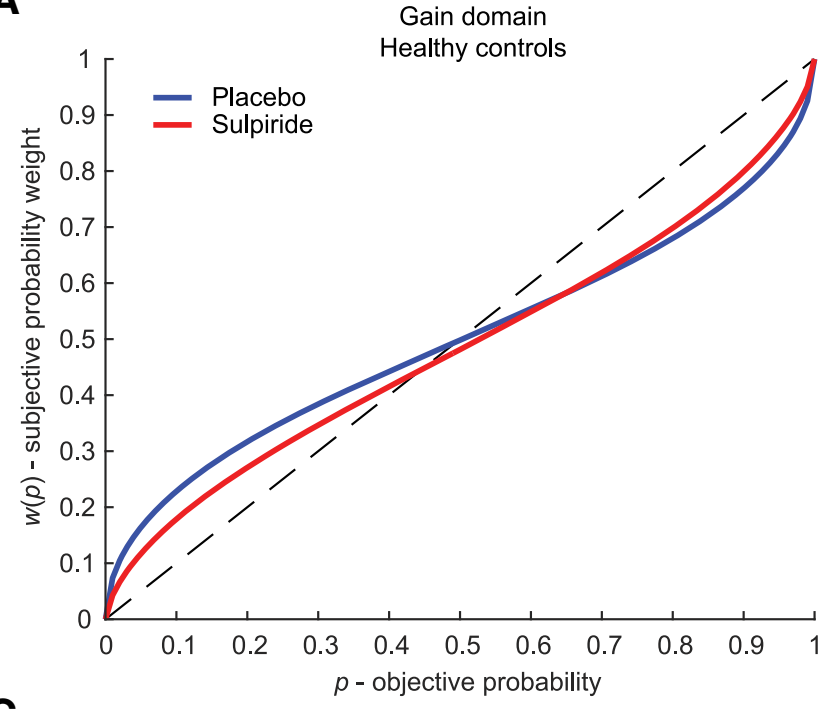

C

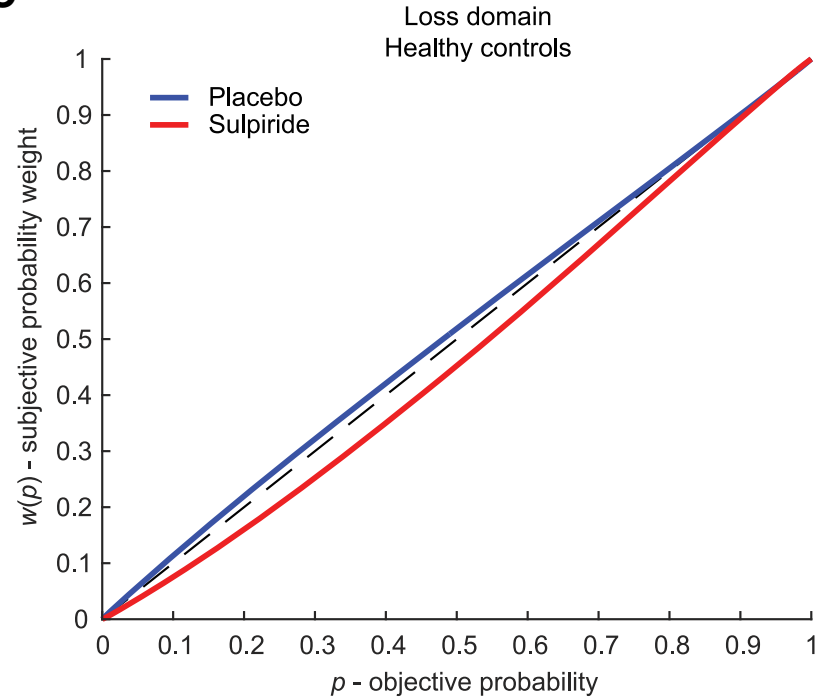

B

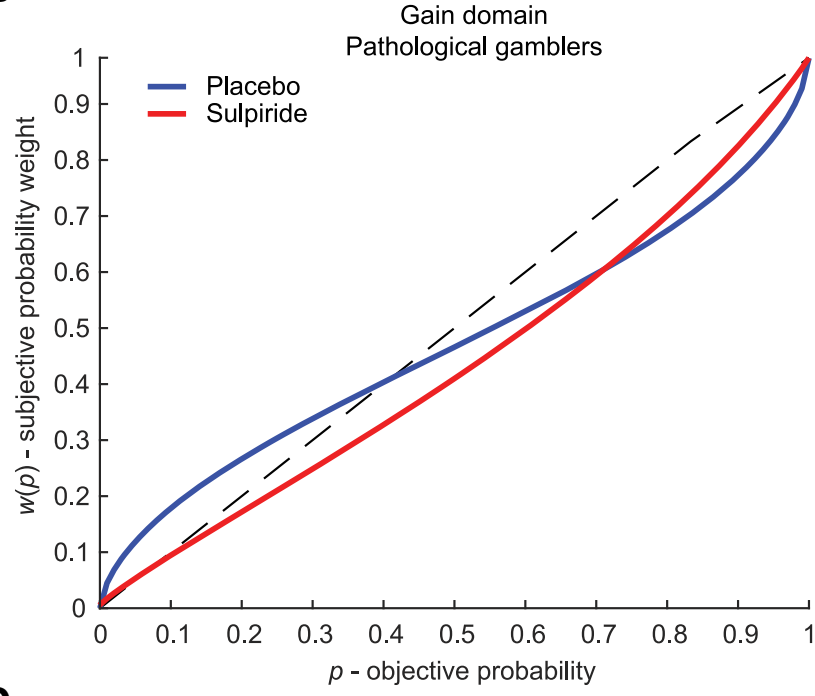

D

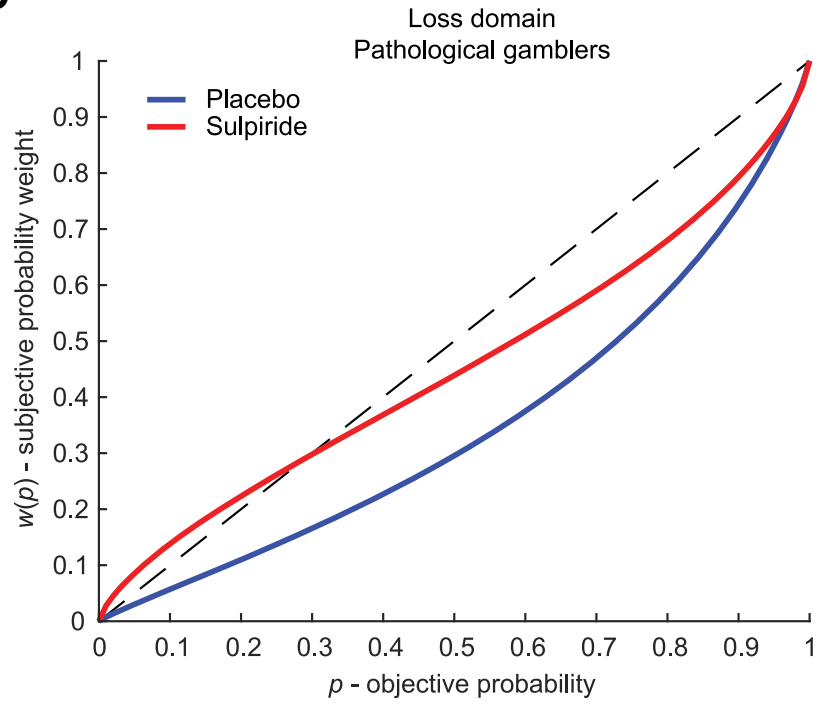

Figure 3. Fitted probability weighting function based on group median estimates of $\delta$ (elevation) and $\gamma$ (distortion). Across groups, sulpiride decreased probability distortion in the gain domain compared with placebo $(\boldsymbol{A}, \boldsymbol{B})$. When examining the placebo condition alone, pathological gamblers showed a decreased elevation of their probability weighting function in the loss domain compared with healthy controls $(\boldsymbol{C}, \boldsymbol{D})$.

pants, i.e., when none of the participants were excluded based on behavioral criteria, leading to 22 healthy controls and 21 pathological gamblers $\left(Z=3.50, p_{\text {uncorr }}=\right.$ $\left.0.00046, p_{\text {corr }}=0.0028, \mathrm{CLE}=0.72\right)$. However, the group effect on the elevation parameter previously observed in the loss/placebo condition did not remain significant when all participants were included, $Z=-2.6, p_{\text {uncorr }}=$ $0.009, p_{\text {corr }}=0.054$, CLE $=0.27$.

Finally, to assess the accuracy of the parameter estimation, we ran a parameter recovery procedure (Heathcote et al., 2015). First, we used the parameter values from the original estimation to simulate new data. Specifically, we generated synthetic certainty equivalents for every gamble (i.e., 10 gambles in the gain the domain and 10 gambles in the loss domain) for each participant and each drug condition, using Equation 2. From there we created 200 noisy synthetic datasets by adding normally distributed noise to these synthetic certainty equivalents; following standards in the field, the standard error of the noise was set to be the median (over all participants and conditions) of the root-mean-squared error between the original and simulated values. We then used these noisy synthetic datasets in combination with the previously described semi-parametric procedure (Abdellaoui et al., 2011), to perform 200 estimations of $w(2 / 6), \alpha, \delta$, and $\gamma$ parameters. Across-subject correlation coefficients between the original and the recovered parameter values (defined as medians over the 200 simulations) were above 0.95 for all parameters in all conditions, indicating efficient parameter recovery and high accuracy in the original parameter estimation. Our main result indicating a significant drug effect on the distortion parameter $\gamma$ showed an even larger effect size with the recovered parameter values $(\mathrm{CLE}=0.76)$ than with the original parameters $(C L E=0.70)$. 


\section{Discussion}

This study investigated the effect of a dopaminergic manipulation on probability weighting during risk-taking in pathological gamblers and healthy participants. In line with our first hypothesis, we found that blocking dopamine $D_{2} / D_{3}$ receptors attenuated probability distortion in the gain domain. However, in contrast to our second hypothesis, the elevation of the probability weighting function was not affected by the dopaminergic manipulation and did not differ between pathological gamblers and healthy controls in the gain domain, although a group difference was observed in the loss domain under placebo. Similarly, we did not find evidence for differences in sensitivity to outcomes between pathological gamblers and healthy controls, as well as no effect of the drug on the sensitivity to outcomes.

Our results demonstrate that the degree of nonlinear probability weighting during decision-making is modulated by dopamine. More specifically, blocking $D_{2} / D_{3}$ receptors decreased probability distortion in the gain domain; this made participants more linear, or rational, in their overall assessment of probabilities, and thus more sensitive to changes in probabilities in the medium range. Such a differential effect of a dopaminergic agent on low versus high probabilities is consistent with several previous studies. First, it is remarkably consistent with a recent study that used a similar paradigm and similar drug (amisulpride), and showed that the selective blockade of $D_{2} / D_{3}$ receptor with amisulpride led to a similar decrease in probability distortion during risky decision-making (Burke et al., 2017). In another study, Norbury et al. (2013) showed that, in low sensation-seeking participants, the dopamine $D_{2} / D_{3}$ receptor agonist cabergoline increased risk-taking for high winning probabilities, while decreasing it for low winning probabilities. Similarly, Stopper et al. (2013) have shown that the administration of a dopamine $D_{1}$ receptor agonist increased risk-taking behavior of rats in the context of high winning probabilities but decreased it in the context of low winning probabilities. Interestingly, in all these studies including ours, the interaction of dopaminergic drug effects with probability level led to more rational behavior maximizing long-term expected value. Thus, it could be that, instead of, or in addition to, inducing a shift in risk taking, modulating dopamine might induce a shift in the adherence to the principle of expected value maximization. This is an intriguing hypothesis that would deserve to be formally tested in future studies.

Particularly relevant for the current study is the work of Takahashi et al. (2010), which to our knowledge is the only study with Burke et al. (2017) to have explicitly investigated the role of dopamine in probability weighting. In their PET study, Takahashi et al. (2010) reported that lower dopamine $D_{1}$, but not $D_{2}$, receptor binding in the striatum was associated with higher levels of probability distortion. This seems partly at odds with the current results, which suggest that that $D_{2}$ receptor stimulation also plays a role in probability weighting. One possibility is that the drug effect observed in the current study could reflect a change in the balance between $D_{1}$ and $D_{2}$ receptor-mediated activity in the direct and indirect pathways of the basal ganglia, respectively, with sulpirideinduced $D_{2} / D_{3}$ receptor blockade being associated with a shift toward $D_{1}$ receptor-dependent Go-pathway activity (Frank and O'Reilly, 2006; Jocham et al., 2011; van der Schaaf et al., 2014). Note that the stimulation of low affinity $D_{1}$ receptors could have been further amplified by the use of a relatively low dose of sulpiride $(400 \mathrm{mg})$, which may also act on presynaptic auto-regulatory $D_{2}$ receptors and thus increase dopamine release (Frank and O'Reilly, 2006). Accordingly, we observed that sulpiride-induced $D_{2} / D_{3}$ receptor blockade decreases distortion, which is in line with the observation of Takahashi et al., that higher $D_{1}$ receptor binding in the striatum is associated with less distortion.

A number of previous studies have shown that dopaminergic manipulations induce a global shift in risk attitudes, i.e., they either increase or decrease risk taking, both in humans (Riba et al., 2008; Djamshidian et al., 2010; Rutledge et al., 2015; Rigoli et al., 2016) and animals (St Onge and Floresco, 2009; Zeeb et al., 2009; Cocker et al., 2012). As mentioned previously, the lack of such an effect in our study could stem from the fact that, in contrast to most of these studies that only manipulated one probability (or a limited range of probabilities), we considered the whole range of probabilities and observed opposite effects for high and low probabilities. Another distinctive feature of our experimental design is the absence of monetary feedback, which was chosen to avoid contamination of the decision-making process by previous outcomes (Schonberg et al., 2011). This is important since risk attitudes, in particular probability distortion, have been shown to differ when making decisions from description, as is the case in our study, versus from experience, i.e., based on feedback (Hertwig and Erev, 2009). In addition, recent evidence in rats suggests that the influence of the dopamine $D_{2}$ pathway on risky behavior is exerted via the signaling of prior outcomes (Zalocusky et al., 2016). Thus, the absence of feedback in our task could explain why the blockade of dopamine $D_{2}$ receptors failed to produce a global effect on risk attitudes. Interestingly, the vast majority of human studies reporting a global shift in risk-taking following a dopaminergic manipulation have used dopamine-enhancing agents such as L-Dopa. Thus far, we are aware of only one study (Burke et al., 2017) reporting similar effects following dopamine $D_{2} / D_{3}$ receptor blockade.

We were not able to replicate our previous result showing an elevation of the probability weighting function in the gain domain (i.e., increased preference for risk) in pathological gamblers compared with healthy controls (Ligneul et al., 2013). One important methodological difference is that the monetary amounts used in the current study were much higher than in our previous study $(€ 300-€ 1200$ vs $€ 2-€ 20$ ). It has been observed that people tend to be more risk seeking for low-stake gambles than large-stake gambles, an observation referred to as the "peanuts effect" (Prelec and Loewenstein, 1991; see also Weber and Chapman, 2005). It is possible that the gamblers in our previous study were particularly sensitive to the peanuts 
effect and engaged in particularly high risk-seeking behavior in the presence of low-stake gambles. It is also possible that the control participants in the current study happened to be more risk seeking than on average. A qualitative comparison of median values for the elevation parameter in the gain domain (Ligneul et al., 2013: $\delta_{\text {Controls }}=$ $0.74, \delta_{\text {Gamblers }}=1.03$; current study: $\delta_{\text {Controls }}=0.99$, $\delta_{\text {Gamblers }}=0.90$ ) with typical values reported in the literature (Fox and Poldrack, 2014, their Table A.3: median $\delta=0.77$ ) lends credence to these hypotheses: it seems that the control participants in the current study were more risk seeking than on average, while the gamblers were less risking than in our previous study.

Another difference is that we assumed a linear value function in our previous study, whereas in the current study we estimated the value function empirically based on the certainty equivalents. Given the trade-off between prospect theory parameters $\alpha$ (curvature parameter of the value function) and $\delta$ (elevation parameter of the probability weighting function) in accounting for risk attitudes (Fox and Poldrack, 2014), it could be that part of the risk-seeking behavior was absorbed by the $\alpha$ parameter in our current modeling procedure, whereas all of it was absorbed by the $\delta$ parameter in the previous study. Note however that our present results remained qualitatively unchanged when the estimation procedure was run with a linear value function, that is, we did not observe group differences in the probability weighting function when using either the linear or power forms of the value function.

While no group difference was observed in the gain domain, analyses restricted to the placebo condition revealed that, in the loss domain, pathological gamblers showed a significant decrease in the elevation of their probability weighting function compared with heathy controls (Fig. $3 C, D$ ). This observation implies a general underweighting of losing probabilities, which could contribute to the optimism bias and excessive risk-taking behavior observed in pathological gamblers. However, given that this result was not predicted and only applies to the placebo condition, we prefer to refrain from speculating further before it is replicated.

This study is not without its limitations. First, we had a modest sample size, partly due to the complexities of running pharmacological studies in patients, and the exclusion of several participants based on outlying behavior and violations of basic prospect theory assumptions. Yet, to mitigate the increased likelihood of false positives (Poldrack et al., 2017), we implemented stringent Bonferroni correction for multiple comparisons and demonstrated the convergence of results across various sensitivity analyses. It should also be noted that our sample was exclusively composed of men, and that further study is necessary to assess whether our results generalize to women, especially given previous evidence of gender differences in probability weighting (Fehr-Duda et al., 2006). Another limitation is the moderate test-retest reliability of decision-making measures in addictive disorders such as pathological gambling (Kräplin et al., 2016). This might have limited our ability to replicate our previous result on the elevation of probability weighting (Ligneul et al., 2013) and more generally our ability to uncover true differences between groups or drug conditions. Furthermore, individual risk preferences have been shown to vary substantially across tasks, a phenomenon known as the "risk elicitation puzzle," partly attributable to inconsistent decision strategies across tasks (Pedroni et al., 2017). This observation warrants some caution regarding the generalizability of the present findings, which could in part be driven by the specific demands of the task that we used. In particular, using a more ecological gambling task might have revealed clearer differences in risk-taking between pathological gamblers and healthy controls (Schonberg et al., 2011).

In summary, this study provides evidence supporting the hypothesis that modulating dopamine affects how humans weight winning probabilities during decision making. Dopamine $D_{2} / D_{3}$ receptor antagonism shifts probability weighting in the direction of more objective, economically rational decision making. In future studies, it will be important to replicate this result and further compare the contributions of $D_{1}$ and $D_{2} / D_{3}$ receptors with the same method, since the effect has now been observed in relation to both receptors (Takahashi et al., 2010).

\section{References}

Abdellaoui M, Bleichrodt H, L'Haridon O (2008) A tractable method to measure utility and loss aversion under prospect theory. J Risk Uncertain 36:245-266. CrossRef

Abdellaoui M, Diecidue E, Öncüler A (2011) Risk preferences at different time periods: an experimental investigation. Manage Sci 57:975-987. CrossRef

American Psychiatric Association (2000) Diagnostic and statistical manual of mental disorders: DSM-IV-TR (4th ed., text rev.). Washington, DC: Author.

Barrus MM, Winstanley CA (2016) Dopamine $D_{3}$ receptors modulate the ability of win-paired cues to increase risky choice in a rat gambling task. J Neurosci 36:785-794. CrossRef Medline

Boileau I, Payer D, Chugani B, Lobo DSS, Houle S, Wilson AA, Warsh J, Kish SJ, Zack M (2014) In vivo evidence for greater amphetamine-induced dopamine release in pathological gambling: a positron emission tomography study with $[(11) \mathrm{C}]-(+)-$ PHNO. Mol Psychiatry 19:1305-1313.

Brainard DH (1997) The psychophysics toolbox. Spat Vis 10:433436. Medline

Burke CJ, Soutschek A, Weber S, Beharelle AR, Fehr E, Haker H, Tobler PN (2017) Dopamine receptor-specific contributions to the computation of value. Neuropsychopharmacology, in press.

Cocker PJ, Dinelle K, Kornelson R, Sossi V, Winstanley CA (2012) Irrational choice under uncertainty correlates with lower striatal D2/3 receptor binding in rats. J Neurosci 32:15450-15457. CrossRef

Djamshidian A, Jha A, O'Sullivan SS, Silveira-Moriyama L, Jacobson C, Brown P, Lees A, Averbeck BB (2010) Risk and learning in impulsive and nonimpulsive patients with Parkinson's disease. Mov Disord 25:2203-2210. CrossRef Medline

Eisenegger C, Naef M, Linssen A, Clark L, Gandamaneni PK, Müller U, Robbins TW (2014) Role of dopamine D2 receptors in human reinforcement learning. Neuropsychopharmacology 39:23662375. CrossRef Medline

Fehr-Duda H, De Gennaro M, Schubert R (2006) Gender, financial risk, and probability weights. Decis Theory 60:283-313. CrossRef

Fox CR, Poldrack RA (2014) Appendix: prospect theory and the brain. In: Neuroeconomics: decision making and the brain (Glim- 
cher PW, Camerer CF, Fehr E, Poldrack RA, eds), pp 533-567. New York: Academic Press.

Frank MJ, Seeberger LC, O'Reilly RC (2004) By carrot or by stick: cognitive reinforcement learning in Parkinsonism. Science 306: 1940-1943. CrossRef Medline

Frank MJ, O'Reilly RC (2006) A mechanistic account of striatal dopamine function in human cognition: psychopharmacological studies with cabergoline and haloperidol. Behav Neurosci 120: 497-517. CrossRef Medline

Gonzalez R, Wu G (1999) On the shape of the probability weighting function. Cogn Psychol 38:129-166. CrossRef Medline

Grissom RJ, Kim JJ (2012) Effect sizes for research: univariate and multivariate applications. Routledge: New York, NY.

Heatherton TF, Kozlowski LT, Frecker RC, Fagerström KO (1991) The Fagerström test for nicotine dependence: a revision of the Fagerström tolerance questionnaire. Br J Addict 86:1119-1127. Medline

Heathcote A, Brown SD, Wagenmakers E-J (2015) An introduction to good practices in cognitive modeling. In: An introduction to modelbased cognitive neuroscience (Forstmann BU, Wagenmakers E-J, eds), pp 25-48. New York: Springer New York.

Hertwig R, Erev I (2009) The description-experience gap in risky choice. Trends Cogn Sci 13:517-523. CrossRef Medline

Hsu M, Krajbich I, Zhao C, Camerer CF (2009) Neural response to reward anticipation under risk is nonlinear in probabilities. J Neurosci 29:2231-2237. CrossRef Medline

Janssen LK, Sescousse G, Hashemi MM, Timmer MHM, Ter Huurne NP, Geurts DEM, Cools R (2015) Abnormal modulation of reward versus punishment learning by a dopamine D2-receptor antagonist in pathological gamblers. Psychopharmacology 232:33453353. CrossRef

Jocham G, Klein TA, Ullsperger M (2011) Dopamine-mediated reinforcement learning signals in the striatum and ventromedial prefrontal cortex underlie value-based choices. J Neurosci 31:16061613. CrossRef Medline

Kahneman D, Tversky A (1979) Prospect theory: an analysis of decision under risk. Econometrica 47:263-291. CrossRef

Kräplin A, Scherbaum S, Bühringer G, Goschke T (2016) Retest reliabilities of decision-making and cognitive control measures in addictive disorders. Sucht 62:191-202. CrossRef

Lattimore PK, Baker JR, Witte AD (1992) The influence of probability on risky choice: a parametric examination. $\mathrm{J}$ Econ Behav Organ 17:377-400. CrossRef

Lesieur H, Blume S (1987) The South Oaks Gambling Screen (SOGS): a new instrument for the identification of pathological gamblers. Am J Psychiatry 144:1184-1188. CrossRef Medline

Ligneul R, Sescousse G, Barbalat G, Domenech P, Dreher J-C (2013) Shifted risk preferences in pathological gambling. Psychol Med 43:1057-1068. CrossRef

Lobo DSS, Aleksandrova L, Knight J, Casey DM, El-Guebaly N, Nobrega JN, Kennedy JL (2015) Addiction-related genes in gambling disorders: new insights from parallel human and pre-clinical models. Mol Psychiatry 20:1002-1010. CrossRef

Lorains FK, Cowlishaw S, Thomas SA (2011) Prevalence of comorbid disorders in problem and pathological gambling: systematic review and meta-analysis of population surveys. Addiction 106:490498. CrossRef Medline

Mata R, Hau R, Papassotiropoulos A, Hertwig R (2012) DAT1 polymorphism is associated with risk taking in the Balloon Analogue Risk Task (BART). PLoS One 7:e39135. CrossRef Medline

Norbury A, Manohar S, Rogers RD, Husain M (2013) Dopamine modulates risk-taking as a function of baseline sensation-seeking trait. J Neurosci 33:12982-12986. CrossRef Medline

Payer D, Balasubramaniam G, Boileau I (2014) What is the role of the $\mathrm{D}_{3}$ receptor in addiction? A mini review of PET studies with $\left[{ }^{11} \mathrm{C}\right]-$ (+)-PHNO. Prog Neuropsychopharmacol Biol Psychiatry 52:4-8. CrossRef

Pedroni A, Frey R, Bruhin A, Dutilh G, Hertwig R, Rieskamp J (2017) The risk elicitation puzzle. Nat Hum Behav 1:803-809. CrossRef
Pessiglione M, Seymour B, Flandin G, Dolan RJ, Frith CD (2006) Dopamine-dependent prediction errors underpin reward-seeking behaviour in humans. Nature 442:1042-1045. CrossRef Medline

Poldrack RA, Baker CI, Durnez J, Gorgolewski KJ, Matthews PM, Munafò M, Nichols TE, Poline J-B, Vul E, Yarkoni T (2017) Scanning the horizon: towards transparent and reproducible neuroimaging research. Nat Rev Neurosci 18:115-126. CrossRef Medline

Prelec D (1998) The probability weighting function. Econometrica 66:497-527. CrossRef

Prelec D, Loewenstein G (1991) Decision making over time and under uncertainty: a common approach. Manage Sci 37:770-786. CrossRef

Riba J, Krämer UM, Heldmann M, Richter S, Münte TF (2008) Dopamine agonist increases risk taking but blunts reward-related brain activity. PLoS One 3:e2479. CrossRef Medline

Rigoli F, Rutledge RB, Chew B, Ousdal OT, Dayan P, Dolan RJ (2016) Dopamine increases a value-independent gambling propensity. Neuropsychopharmacology 41:2658-2667. CrossRef Medline

Rutledge RB, Skandali N, Dayan P, Dolan RJ (2015) Dopaminergic modulation of decision making and subjective well-being. J Neurosci 35:9811-9822. CrossRef Medline

Saunders JB, Aasland OG, Babor TF, De la Fuente JR, Grant M (1993) Development of the Alcohol Use Disorders Identification Test (AUDIT): WHO collaborative project on early detection of persons with harmful alcohol consumption-II. Addiction 88:791804. Medline

Schonberg T, Fox CR, Poldrack RA (2011) Mind the gap: bridging economic and naturalistic risk-taking with cognitive neuroscience. Trends Cogn Sci 15:11-19. CrossRef Medline

Seeman P (2015) Parkinson's disease treatment may cause impulsecontrol disorder via dopamine D3 receptors. Synapse 69:183-189. CrossRef Medline

Sescousse G, Janssen LK, Hashemi MM, Timmer MHM, Geurts DEM, ter Huurne NP, Clark L, Cools R (2016) Amplified striatal responses to near-miss outcomes in pathological gamblers. Neuropsychopharmacology 41:2614-2623. CrossRef

Sheehan D, Lecrubier Y, Harnett-Sheehan K, Amorim P, Janavs J, Weiller ETH, Hergueta T, Baker RDG, Dunbar G (1998) Diagnostic Psychiatric Interview for DSM-IV and ICD-10. Journal of Clinical Psychiatry 59:22-33.

St Onge JR, Floresco SB (2009) Dopaminergic modulation of riskbased decision making. Neuropsychopharmacology 34:681-697. CrossRef Medline

St Onge JR, Chiu YC, Floresco SB (2010) Differential effects of dopaminergic manipulations on risky choice. Psychopharmacology 211:209-221. CrossRef Medline

Stopper CM, Khayambashi S, Floresco SB (2013) Receptor-specific modulation of risk-based decision making by nucleus accumbens dopamine. Neuropsychopharmacology 38:715-728. CrossRef Medline

Takahashi $\mathrm{H}$, Matsui $\mathrm{H}$, Camerer CF, Takano H, Kodaka F, Ideno T, Okubo S, Takemura K, Arakawa R, Eguchi Y, Murai T, Okubo Y, Kato M, Ito H, Suhara T (2010) Dopamine D1 receptors and nonlinear probability weighting in risky choice. J Neurosci 30 : 16567-16572. CrossRef

Timmer MHM, Sescousse G, Esselink RAJ, Piray P, Cools R (2017) Mechanisms underlying dopamine-induced risky choice in Parkinson's disease with and without depression (history). Comput Psych 2:11-27.

van der Schaaf ME, Van Schouwenburg MR, Geurts DEM, Schellekens AFA, Buitelaar JK, Verkes RJ, Cools R (2014) Establishing the dopamine dependency of human striatal signals during reward and punishment reversal learning. Cereb Cortex 24:633-642. CrossRef

van Enkhuizen J, Henry BL, Minassian A, Perry W, Milienne-Petiot M, Higa KK, Geyer MA, Young JW (2014) Reduced dopamine transporter functioning induces high-reward risk-preference consistent 
with bipolar disorder. Neuropsychopharmacology 39:3112-3122. CrossRef Medline

van Holst RJ, Sescousse G, Janssen LK, Janssen M, Berry AS, Jagust WJ, Cools R (2017) Increased striatal dopamine synthesis capacity in gambling addiction. Biol Psychiatry, in press.

von Bahr C, Wiesel F, Movin G, Eneroth P, Jansson P, Nilsson L, Ogenstad S (1991) Neuroendocrine responses to single oral doses of remoxipride and sulpiride in healthy female and male volunteers. Psychopharmacology 103:443-448. Medline

Voon V, Fernagut PO, Wickens J, Baunez C, Rodriguez M, Pavon N, Juncos JL, Obeso JA, Bezard E (2009) Chronic dopaminergic stimulation in Parkinson's disease: from dyskinesias to impulse control disorders. Lancet Neurol 8:1140-1149. CrossRef Medline Voon V, Gao J, Brezing C, Symmonds M, Ekanayake V, Fernandez H, Dolan RJ, Hallett M (2011) Dopamine agonists and risk: impulse control disorders in Parkinson's disease. Brain 134:1438-1446. CrossRef Medline

Weber BJ, Chapman GB (2005) Playing for peanuts: why is risk seeking more common for low-stakes gambles? Organ Behav Hum Decis Process 97:31-46. CrossRef

Wuensch K (2015) CL: The Common Language Effect Size Statistic. Retrieved from http://core.ecu.edu/psyc/wuenschk/docs30/CL.pdf on the 6th of July, 2017.

Zalocusky KA, Ramakrishnan C, Lerner TN, Davidson TJ, Knutson B, Deisseroth K (2016) Nucleus accumbens D2R cells signal prior outcomes and control risky decision-making. Nature 531:642-646. CrossRef Medline

Zeeb FD, Robbins TW, Winstanley CA (2009) Serotonergic and dopaminergic modulation of gambling behavior as assessed using a novel rat gambling task. Neuropsychopharmacology 34:23292343. CrossRef Medline

Zhong S, Israel S, Xue H, Sham PC, Ebstein RP, Chew SH (2009) A neurochemical approach to valuation sensitivity over gains and losses. Proc Biol Sci 276:4181-4188. CrossRef

Zigmond AS, Snaith RP (1983) The hospital anxiety and depression scale. Acta Psychiatr Scand 67:361-370. Medline 